\title{
Dark matter in archaeal genomes: a rich source of novel mobile elements, defense systems and secretory complexes
}

\author{
Kira S. Makarova $\cdot$ Yuri I. Wolf · Patrick Forterre • \\ David Prangishvili • Mart Krupovic • \\ Eugene V. Koonin
}

Received: 9 April 2014/ Accepted: 6 July 2014/Published online: 12 August 2014

(C) The Author(s) 2014. This article is published with open access at Springerlink.com

\begin{abstract}
Microbial genomes encompass a sizable fraction of poorly characterized, narrowly spread fast-evolving genes. Using sensitive methods for sequences comparison and protein structure prediction, we performed a detailed comparative analysis of clusters of such genes, which we denote "dark matter islands", in archaeal genomes. The dark matter islands comprise up to $20 \%$ of archaeal genomes and show remarkable heterogeneity and diversity. Nevertheless, three classes of entities are common in these genomic loci: (a) integrated viral genomes and other mobile elements; (b) defense systems, and (c) secretory and other membraneassociated systems. The dark matter islands in the genome of thermophiles and mesophiles show similar general trends of gene content, but thermophiles are substantially enriched in predicted membrane proteins whereas mesophiles have a greater proportion of recognizable mobile elements. Based on this analysis, we predict the existence of several novel groups of viruses and mobile elements, previously unnoticed variants of CRISPR-Cas immune systems, and new secretory
\end{abstract}

This article is part of a special issue based on the 10th International Congress on Extremophiles held in Saint Petersburg, Russia, September 7-11, 2014.

Communicated by E. Bonch-Osmolovskaya.

Electronic supplementary material The online version of this article (doi:10.1007/s00792-014-0672-7) contains supplementary material, which is available to authorized users.

K. S. Makarova · Y. I. Wolf · E. V. Koonin ( $\bowtie)$

National Center for Biotechnology Information, National

Library of Medicine, Bethesda, MD 20894, USA

e-mail: koonin@ncbi.nlm.nih.gov

P. Forterre $\cdot$ D. Prangishvili $\cdot$ M. Krupovic

Institut Pasteur, Unité Biologie Moléculaire Du Gène Chez Les

Extrêmophiles, 25 Rue Du Docteur Roux, 75015 Paris, France systems that might be involved in stress response, intermicrobial conflicts and biogenesis of novel, uncharacterized membrane structures.

Keywords Archaeal genomes · ORFans - Genomic islands · Integration · Viruses · Defense

\section{Introduction}

Genes of bacteria and archaea widely differ with respect to their phyletic spread and, by inference, the rates of gain and loss (Bellgard et al. 1999; Kolsto 1997; Koonin and Galperin 1997; Koonin and Wolf 2008; Wolf et al. 2012). Although the distribution of gene turnover rates is likely to be contiguous, the apparent qualitative differences between their occurrence patterns gave rise to the "core, shell, cloud" classification (Koonin and Wolf 2008; Makarova et al. 2007). Core genes are nearly ubiquitous and are enriched for components of the information processing machinery, primarily translation. Genes involved in metabolism and basic cellular processes belong to a wide class of shell genes; these genes comprise the majority of the genes in each individual prokaryotic genome. Most of the gene families, including singletons, also known as "ORFans" (Cortez et al. 2009; Siew and Fischer 2003; Yin and Fischer 2006), belong to the cloud of rare and/or narrowly distributed genes. They encompass only $10-20 \%$ of the genes in each individual genome, but collectively these rare genes dominate the prokaryotic genetic space (Koonin and Wolf 2008).

The great majority of the cloud genes, especially ORFans, lack functional assignments because due to their rarity that is often coupled to fast evolution they are rarely characterized experimentally and are not readily amenable to informative computational analysis. However, many of those "cloud" 
genes that have been experimentally and/or computationally characterized, belong to one of the two functional classes: (a) the widely defined mobilome that is characterized by selfsustained ability to propagate semi-independently from their host genomes (various kinds of transposable elements, plasmids and viruses) and (b) defense systems that are prone to horizontal gene transfer due to the selection pressure that virus predation and other stress factors exert on microbes (Cortez et al. 2009; Daubin and Ochman 2004; Makarova et al. 2013b; Makarova et al. 2011b, c). Recently, the content of integrated viruses and plasmids in bacterial and archaeal genomes has been shown to be substantially higher and more diverse than previously suspected (Cortez et al. 2009; Krupovic and Bamford 2008a; Krupovic and Forterre 2011; Krupovic et al. 2011; Prangishvili 2013). In particular, multiple proviruses have been identified in archaea, and it has been shown that not only tailed bacteriophages, well known to integrate into bacterial chromosomes, but also ssDNA viruses form numerous proviruses (Krupovic and Forterre 2011). In parallel, in recent years, fueled in large by the discovery of the CRISPR-Cas systems of archaeal and bacterial adaptive immunity and their application in genome engineering (Barrangou and Horvath 2012; Kim and Kim 2014; Makarova et al. 2013a, b; Marraffini and Sontheimer 2010), comparative genomic and experimental studies have revealed an unsuspected diversity of prokaryotic defense systems that function on the principles of innate immunity, adaptive immunity or programmed cell death (Makarova et al. 2013a, b; Olovnikov et al. 2013; Swarts et al. 2014). Furthermore, it has been shown that analogous to previously characterized pathogenicity and symbiosis islands, genes encoding components of defense systems tend to form cluster in bacterial and archaeal genomes. Accordingly, such clusters have been dubbed defense islands (Makarova et al. 2011c).

The recent unexpected discoveries on the diversity of the mobilome and the defense repertoire of bacterial and archaeal genomes prompted us to systematically explore the archaeal cloud of rare genes. In particular, we aimed at the characterization of clusters of rare genes, identification of previously unnoticed functional themes, and delineation of possible differences between extremophiles and mesophiles.

\section{Materials and methods}

Identification of dark matter genes

A 2013 update of the archaeal clusters of orthologous genes (arCOGs) was used to annotate protein-coding genes in 147 archaeal genomes (Wolf et al. 2012); the results of this genome annotation are available at the NCBI FTP site (ftp:// ftp.ncbi.nih.gov/pub/wolf/COGs/arCOG/). Genome sequences were downloaded from the NCBI FTP site (ftp://
ftp.ncbi.nlm.nih.gov/genomes/Bacteria/). Phyletic patterns (patterns of presence-absence of proteins families) were derived from the respective arCOGs assignments; all genes that were not assigned to arCOGs were included in the analysis as ORFans. Only arCOGs represented in at most 5 archaeal genomes that are either uncharacterized or are annotated as virus-related were chosen for the subsequent indepth analysis. Thus, the "dark matter" gene set includes this subset of small, uncharacterized arCOGs and all ORFans.

\section{Sequence analysis}

Iterative profile searches with the PSI-BLAST (Altschul et al. 1997), with a cut-off e-value of 0.01, compositionbased statistics and low complexity filtering turned off were used to search for distantly similar sequences in NR database. Additionally, another sensitive method for remote homology identification, HHpred, was used with default parameters (Soding et al. 2005).

Similarity based clustering was performed using the BLASTCLUST program (ftp://ftp.ncbi.nih.gov/blast/docu ments/blastclust.html) to cluster sequences at different thresholds. Multiple sequence alignments were built using PROMALS3D (Pei et al. 2008) and adjusted manually on the basis of the PSI-BLAST and HHpred search results. Protein secondary structure was predicted using Psi-Pred (Jones 1999).

Direct repeats corresponding to the attachment sites of bacteriophages were searched for using UGENE (Okonechnikov et al. 2012). For gene neighborhoods analysis of selected genes, 10 upstream and downstream genes were extracted. For each analyzed gene, the pfam identifiers and COG numbers as well as the corresponding annotations were assigned using RPS-BLAST program and CDD database of profiles (Marchler-Bauer et al. 2009).

Transmembrane segments were predicted using the TMMHMM v. 2.0c program with default parameters (Krogh et al. 2001). Signal peptides were predicted using the SignalP v. 4.1c program; the union of the three predictions (gram-negative, gram-positive and eukaryotic models) was used (Petersen et al. 2011).

Statistical analysis was performed in $\mathrm{R}$ environment. The probability density curves were obtained by Gaussiankernel smoothing of the individual data points (Parzen 1962).

\section{Results and discussion}

Identification of dark matter islands in archaeal genomes and their major characteristics

We used the arCOGs database to identify the part of the archaeal gene "cloud" that consists of ORFans and genes 


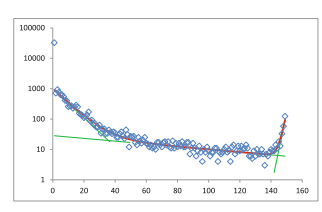

commonality distribution

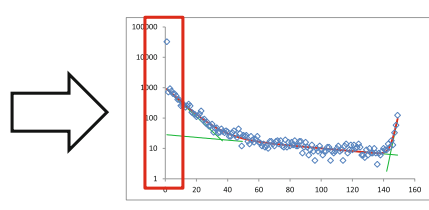

the least common genes

Fig. 1 A schematic of the computational procedure for delineation of the dark matter islands in archaeal genomes. The commonality (gene frequency) plot is based on arCOGs for 146 archaeal genomes and

with a very narrow spread that, in addition, are not functionally characterized. Specifically, gene families represented in at most 5 archaeal genomes (Fig. 1) that are either uncharacterized or are annotated as virus-related were chosen for further analysis as the genomic "dark matter" (Supplementary Table 1). All "dark matter" genes were mapped to the corresponding genome partitions (chromosomes or plasmids). All contiguous 5-gene regions that contained at least 4 "dark matter" genes were marked as "island seeds"; overlapping seeds were merged into "dark matter islands" (Fig. 1). The rationale behind this approach is twofold. First, both genes comprising the archaeal and bacterial mobilomes and genes involved in antivirus defense that together represent a substantial part of the rare gene cloud, tend to form genomic islands (Makarova et al. 2013a, b; Makarova et al. 2011c). Second, shared genomic context increases the chance to obtain functional prediction and to minimize the impact of standalone spurious ORFs that originate from errors of ORF prediction (Aravind 2000; Galperin and Koonin 2000).

Altogether we detected 1611 dark matter islands (Supplementary Table 1) that represent from $0 \%$ (Pyrococcus abyssi GE5, Caldisphaera lagunensis DSM 15908 and Metallosphaera sedula DSM 5348) to $22 \%$ (Cenarchaeum symbiosum A and Candidatus Nitrososphaera gargensis Ga9.2) of the total number of genes in archaeal genomes, with a mean of $3.8 \%$ (Fig. 2a). The two genomes with the highest content of dark matter islands belong to the phylum Thaumarchaea that remains poorly represented among the sequenced genomes and thus possess many lineage-specific uncharacterized genes. Thermophiles generally contain fewer dark matter genes in their genomes compared to mesophiles; in part, this difference can be explained by the fact that several mesophilic archaea possess large genomes that do not have many close relatives among the completely sequenced genomes.

The characteristics of predicted proteins that comprise the dark matter differ from the respective characteristics of randomly sampled archaeal proteins. Thus, the dark matter is strongly enriched in small proteins (Fig. 3a).

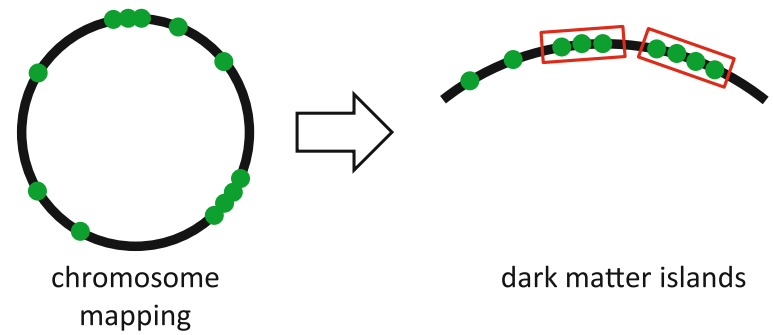

built as described previously (Wolf et al. 2012). Green dots are genes on the chromosome

Approximately $28 \%$ of the dark matter proteins are predicted to contain at least one transmembrane segment, and additional $\sim 3 \%$ are non-membrane proteins with predicted signal peptides, compared to approximately 18 and $2 \%$, respectively, in a random sample of non-dark matter archaeal genes with the same length distribution (Fig. 3b). Thus, the rare, fast-evolving archaeal genes are enriched in integral membrane proteins and secreted proteins that are likely to be involved in transport, signal transduction, communication and defense functions.

Compared to mesophiles, genes in dark matter islands of thermophilic archaea are somewhat longer (median length of 131 vs. 119 codons, $t$ test $p$ value of $1 \times 10^{-6}$ for $\log$ lengths) and contain substantially more transmembrane proteins (39 vs. $26 \%, \chi^{2} p$ value $\ll 10^{-10}$ ) and slightly more proteins with signal peptides (11 vs. $9 \%, \chi^{2} p$ value 0.014) (Fig. 2b).

Most abundant protein families in dark matter islands

Because our procedure allowed one arCOG from the "negative" (non-dark matter) gene set per a 5-gene island (see above), it is not surprising that many of the functionally characterized genes in the dark matter islands belong to this group (Table 1). Nevertheless, it is notable that most of these arCOGs clearly include bona fide mobilome genes such as integrases, transposases and proteins of apparent viral origin (Table 1). Such high prevalence of mobilome components indicates that many of the dark matter islands consist of or include various classes of mobile elements. Several families that were not associated with mobile elements included various (predicted) membrane proteins. A notable example is arCOG01996 that consists of uncharacterized membrane proteins that are present in Archaeoglobi, Pyrococci and several methanogens, including Methanococcales, where these genes form clusters with genes encoding several other membrane proteins (Fig. 4a). In the vicinity of this locus, Methanococcales encode a predicted ABC-type transporter related to the antimicrobial peptide transport 
Fig. 2 Comparison of the features of dark matter islands in archaeal thermophiles and mesophiles. a Distribution of the fraction of genome occupied by dark matter islands in mesophiles (M) and thermophiles (T). b Fraction of proteins containing low complexity segments, predicted transmembrane domains and predicted signal peptides in mesophiles (M) and thermophiles (T). c Fraction of different integrated elements in mesophiles (M) and

thermophiles (T). The figure shows the data obtained with a non-redundant set of thermophile and mesophile genomes that included a single representative genome for each species, in order to eliminate biases potentially caused by the availability of genomes from multiple strains from some but not other species
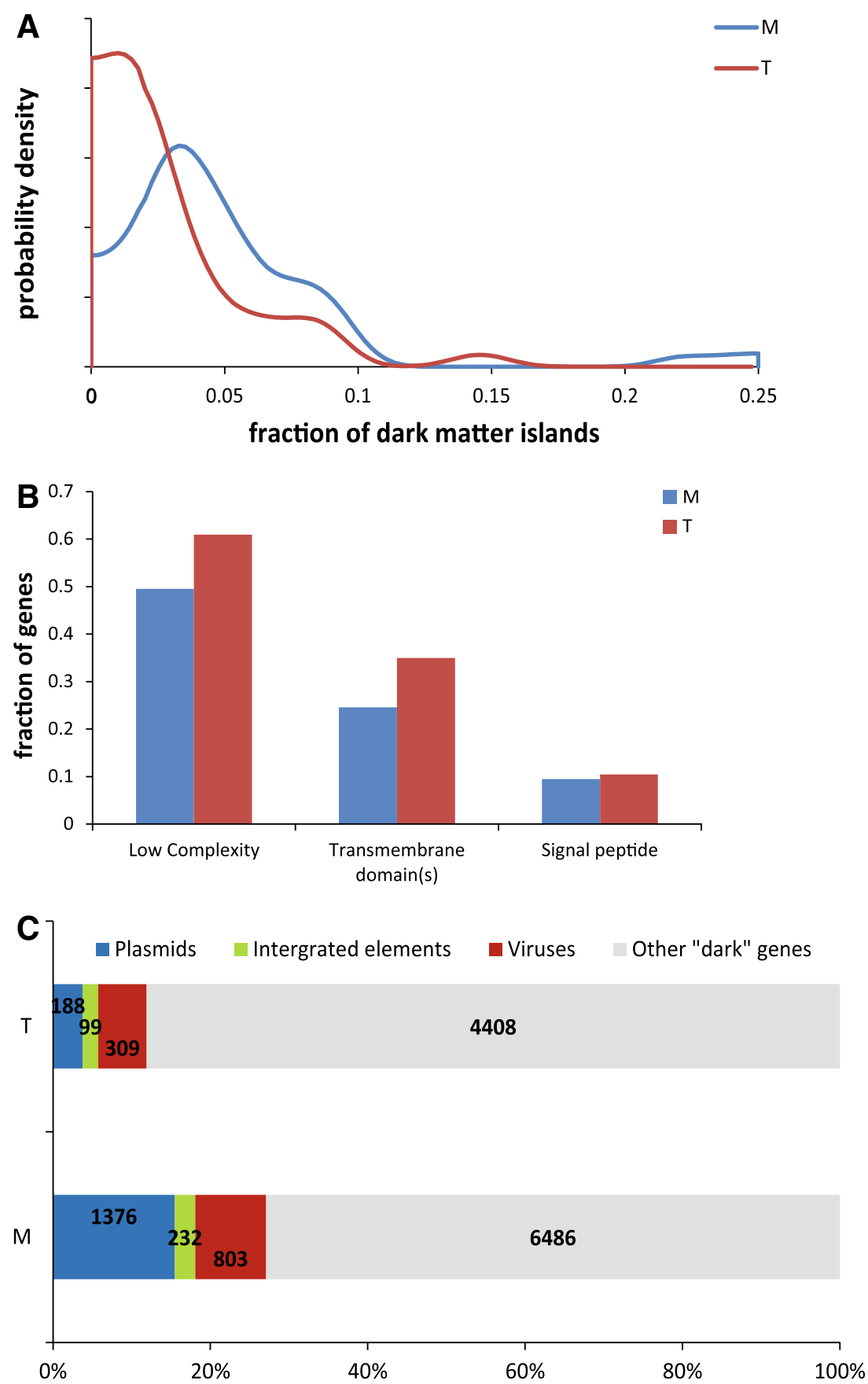

system SalXY, whereas some Pyrococci encode components of restriction-modification systems (Fig. 4a). These observations suggest that such loci encode novel membrane-associated defense systems containing multiple highly variable membrane-associated components (see below). Another abundant protein family (arCOG00194) in the islands is the ATPase component of an ABC-type transporter. The ATPase gene forms a predicted operon with a 6-transmembrane protein, a predicted permease, and a putative substrate-binding protein. Both the putative permease and the binding protein are highly diverged and show only limited sequence similarity to homologs from other genomes (Fig. 4b). It appears likely that these predicted transport systems are involved in resistance to multiple antibiotics and/or other environmental chemicals, similar to bacterial multidrug resistance transporters. Radical SAM superfamily enzymes of arCOG00938 are encoded outside of any conserved context but along which arCOG00288, nitroreductase, represented the few small molecule-metabolizing 

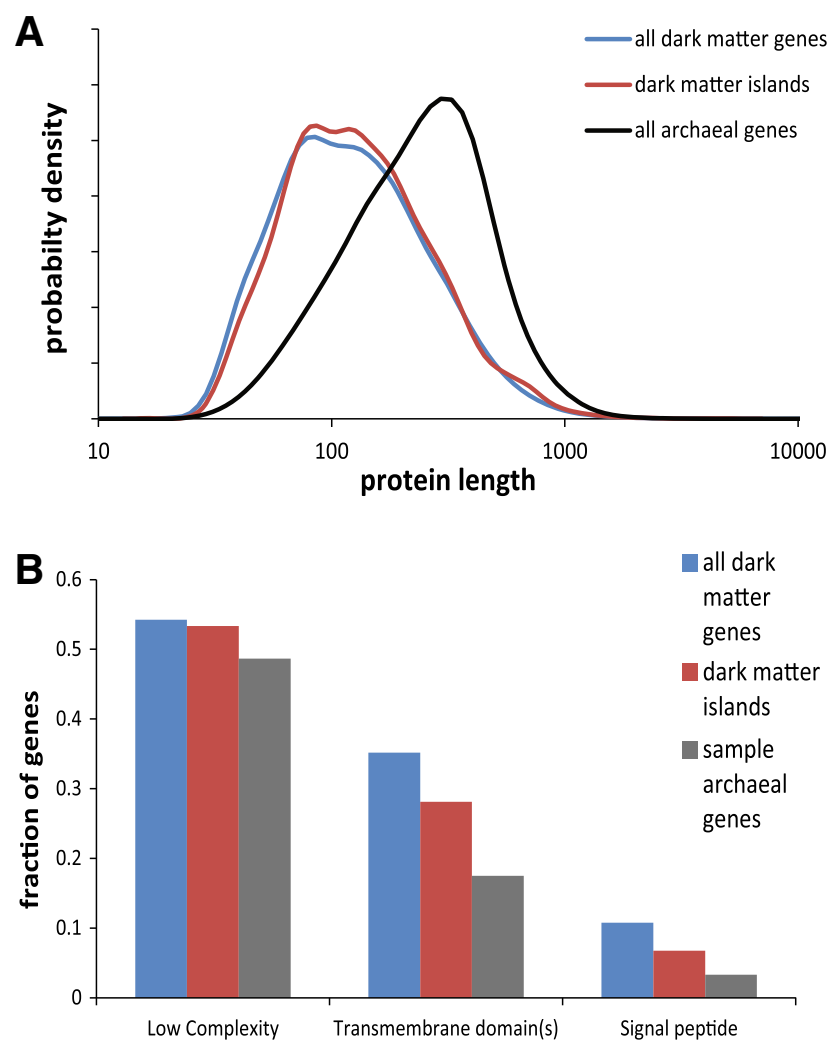

Fig. 3 Comparison of the proteins encoded in dark matter islands with random samples of archaeal proteins. a Distribution of protein lengths in archaeal genomes, all dark matter genes and genes in dark matter islands. b Fraction of proteins containing low complexity segments, predicted transmembrane domains and predicted signal peptides in archaeal genomes (sample of genes with the same distribution of lengths as in dark matter islands), all dark matter genes and genes in dark matter islands

enzymes that are over-represented in the islands (Table 1; Supplementary Table 1). It seems likely that these enzymes are involved in stress response and cellcleaning functions.

In contrast to the over-represented genes from the negative set, among the over-represented arCOGs that were previously annotated as uncharacterized, only a few can be linked to the mobilome (Table 2), e.g., predicted nucleases of the PD-DEXK superfamily (arCOG09441), that appear to be linked to plasmid-like integrated elements (see below). Strikingly, most of these genes, many of which are lineage-specific, encode predicted secreted or membrane proteins (Table 2). For some of these proteins, we were able to identify remote sequence similarity with known protein families such as extracellular proteases (arCOG10864, arCOG06558). Some of these membrane-associated arCOGs form predicted operons although their specific functions remain obscure (see the section on "Predicted new secretion systems" below).

Table 1 Top 20 most common arCOGs from the "negative set" in the dark matter islands

\begin{tabular}{|c|c|c|c|}
\hline $\operatorname{arCOG}$ & $\begin{array}{l}\text { Number } \\
\text { in } \\
\text { islands }\end{array}$ & Annotation & Comment \\
\hline $\operatorname{arCOG} 01241$ & 31 & Integrase & \\
\hline $\operatorname{arCOG01057}$ & 21 & $\begin{array}{l}\text { Predicted } \\
\text { transcriptional } \\
\text { regulator, wHTH }\end{array}$ & Virus associated \\
\hline $\operatorname{arCOG} 00280$ & 21 & HerA-like helicase & $\begin{array}{l}\text { Possible viral } \\
\text { DNA } \\
\text { pumping } \\
\text { ATPase or } \\
\text { viral helicase }\end{array}$ \\
\hline $\operatorname{arCOG01996}$ & 17 & $\begin{array}{l}\text { Uncharacterized } \\
\text { membrane protein }\end{array}$ & $\begin{array}{l}\text { DUF95/ } \\
\text { COG1300, } \\
\text { present in } \\
\text { many bacteria } \\
\text { and archaea }\end{array}$ \\
\hline $\operatorname{arCOG07960}$ & 16 & $\begin{array}{l}\text { SSV 'DnaA-like } \\
\text { protein' ATPase } \\
\text { (AAA+superfamily) }\end{array}$ & Virus associated \\
\hline $\operatorname{arCOG02134}$ & 15 & Transposase & \\
\hline $\operatorname{arCOG01245}$ & 15 & Integrase & \\
\hline $\operatorname{arCOG} 01242$ & 14 & Integrase & \\
\hline $\operatorname{arCOG00194}$ & 14 & $\begin{array}{l}\text { ABC-type multidrug } \\
\text { transport system, } \\
\text { ATPase component }\end{array}$ & $\begin{array}{l}\text { ABC ATPase } \\
\text { associated } \\
\text { often } \\
\text { associated } \\
\text { with } \\
\text { membrane } \\
\text { protein, likely } \\
\text { exporter }\end{array}$ \\
\hline
\end{tabular}

$\operatorname{arCOG00439} 14$

$\operatorname{arCOG00467\quad 13}$

$\operatorname{arCOG03162~} 12$

$\operatorname{arCOG03032\quad 12}$

$\operatorname{arCOG06160~} 11$

$\operatorname{arCOG01308\quad 10}$

$\operatorname{arCOG03924\quad 10}$

$\operatorname{arCOG03166~9~}$
ATPase involved in replication control, Cdc46/Mcm family

Orc/Cdc6-related protein, AAA superfamily ATPase

Site-specific recombinase, DNA invertase pin homolog

Radical SAM superfamily enzyme

TPR repeats containing protein

Transposase

ATPase of the AAA + class, CDC48 family

\section{Transcriptional regulator, MarR family}

AAA + superfamily ATPase fused to HTH and RecB nuclease domains
Virus associated

Virus associated

Virus/plasmid associated

Virus/plasmid associated

Likely involved in defense (or some plasmid gene) 
Table 1 continued

\begin{tabular}{|c|c|c|c|}
\hline $\operatorname{arCOG}$ & $\begin{array}{l}\text { Number } \\
\text { in } \\
\text { islands }\end{array}$ & Annotation & Comment \\
\hline arCOG01055 & 9 & $\begin{array}{l}\text { Transcriptional } \\
\text { regulator, MarR } \\
\text { family }\end{array}$ & $\begin{array}{l}\text { Virus/plasmid } \\
\text { associated } \\
\text { paralog of } \\
\text { arCOG03924 }\end{array}$ \\
\hline arCOG07102 & 9 & $\begin{array}{l}\text { PD-(D/E)XK } \\
\text { superfamily } \\
\text { nuclease }\end{array}$ & $\begin{array}{l}\text { Virus/plasmid } \\
\text { associated }\end{array}$ \\
\hline
\end{tabular}

$\overline{\text { Genes that belong to the mobilome genes are highlighted by bold type }}$
Dark matter and integrated elements

Recently, substantial progress has been achieved in the characterization of archaeal viruses including those that are able to integrate in the host genomes (Prangishvili 2013). Among these, the most abundant and well characterized are members of the orders Ligamenvirales and Caudavirales, and the family Fuselloviridae (Krupovic et al. 2014; Prangishvili et al. 2013; Sencilo and Roine 2014).Two proviruses in Aeropyrum pernix have been recently identified first by in silico analysis and subsequently experimentally demonstrated to be inducible into lytic viruses

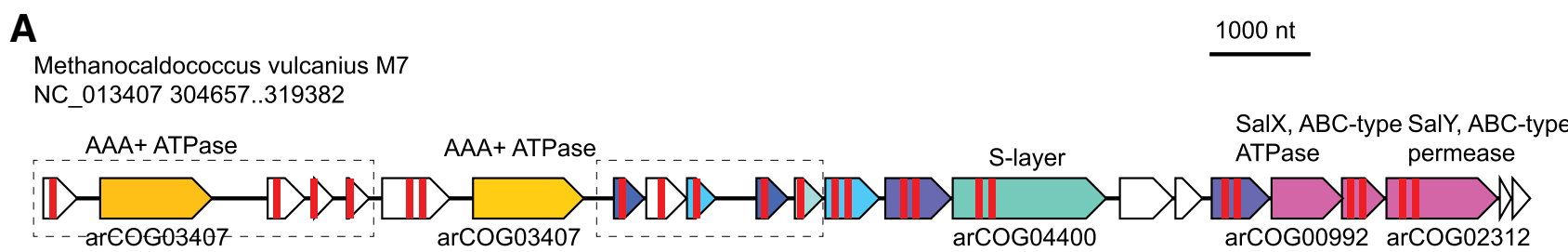

Methanococcus aeolicus Nankai 3 NC_009635 539528..550981

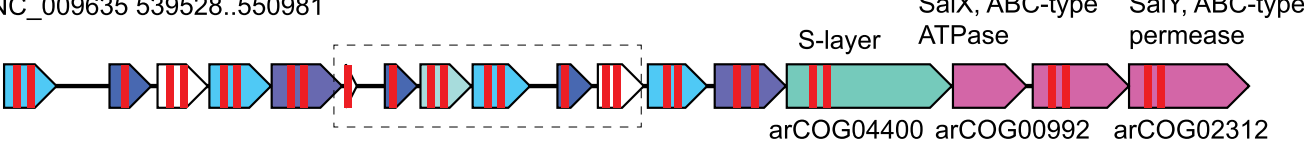

Pyrococcus ST04 NC $017946184756 . .187024$

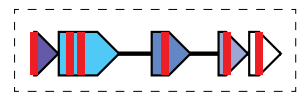

B

Thermococcus AM4 NC_016051 1140535..1143996

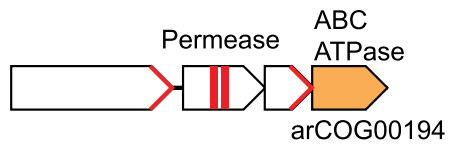

Aciduliprofundum MAR08 339 NC $019942643970 . .646972$

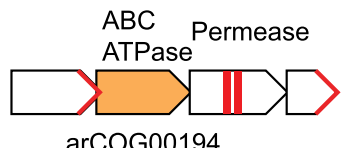

Pyrococcus horikoshii OT3 NC_000961 775061..782324

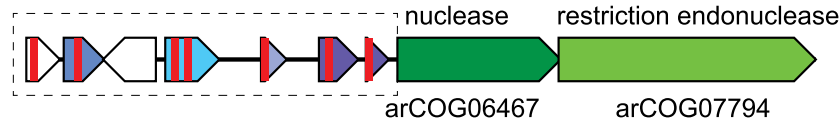

Staphylothermus hellenicus DSM 12710 NC_014205 $499627 . .503095$

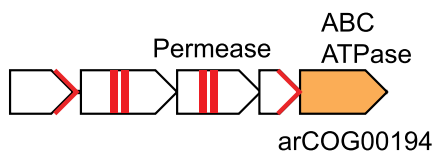

Pyrolobus fumarii $1 \mathrm{~A}$ NC_015931 442176..438895

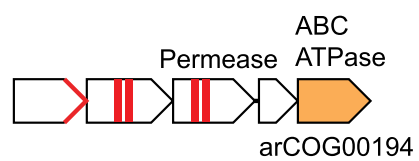

Desulfurococcus mucosus DSM 2162 NC_014961 455989..453524

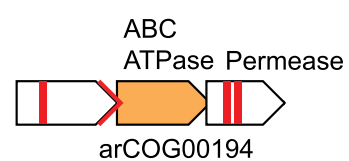

Fig. 4 Neighborhood analysis of selected membrane-associated gene systems among the frequent arCOGs in dark matter. a A predicted $\mathrm{ABC}$ transporter potentially involved in antimicrobial peptide transport. b A membrane-associated system with variable gene cassettes. For each gene neighborhood, the organism name, genome partition and coordinates of the locus are indicated. Genes are shown by block arrows with the length roughly proportional to the size of the corresponding gene. Homologous genes are shown by the same color.
Genes that belong to the respective dark matter island are denoted by dashed boxes. The positions of the predicted transmembrane segments are shown by thick vertical red lines inside the arrows showing the respective genes. Predicted signal peptides in putative secreted proteins are shown by red angular brackets at the ends of the respective arrows. The annotated arCOGs are indicated underneath the respective arrows; brief annotations of the proteins are shown above the arrows 
Table 2 Top 20 most abundant uncharacterized arCOGs in "dark matter islands"

\begin{tabular}{|c|c|c|}
\hline $\operatorname{arCOG}$ & $\begin{array}{l}\text { Number in } \\
\text { islands }\end{array}$ & Annotation and comment \\
\hline $\operatorname{arCOG08821}$ & 18 & $\begin{array}{l}\text { Membrane protein, expanded in } \\
\text { Thaumarchaeota }\end{array}$ \\
\hline $\operatorname{arCOG} 10873$ & 14 & Membrane protein \\
\hline $\operatorname{arCOG} 10027$ & 12 & $\begin{array}{l}\text { Thermococcus specific secreted protein, } \\
\text { paralogs belong to arCOG10066 and } \\
\text { arCOG10028, they form genes clusters }\end{array}$ \\
\hline $\operatorname{arCOG10864}$ & 11 & $\begin{array}{l}\text { Predicted peptidase of C39 family; } \\
\text { possibly associated with pseudo- } \\
\text { murein binding domains }\end{array}$ \\
\hline $\operatorname{arCOG10897}$ & 10 & Small membrane protein \\
\hline $\operatorname{arCOG06558}$ & 10 & $\begin{array}{l}\text { Likely a secreted protease, Propeptide } \\
\text { PepSY and peptidase M4 }\end{array}$ \\
\hline $\operatorname{arCOG} 10066$ & 9 & $\begin{array}{l}\text { Thermococcus specific secreted protein, } \\
\text { same as (see arCOG10027) }\end{array}$ \\
\hline $\operatorname{arCOG10865}$ & 9 & Methanobacterium specific \\
\hline $\operatorname{arCOG09441}$ & 8 & $\begin{array}{l}\text { HJR family endonuclease, PD-DEXK } \\
\text { superfamily, associated with } \\
\text { arCOG07809, viral Primase fused to } \\
\text { AAA DnaA-like ATPAse and Zn } \\
\text { finger domain }\end{array}$ \\
\hline $\operatorname{arCOG} 10959$ & 8 & $\begin{array}{l}\text { Virus/plasmid associated, often co- } \\
\text { occur with primase in particular } \\
\text { arCOG06914 }\end{array}$ \\
\hline $\operatorname{arCOG09176}$ & 8 & $\begin{array}{l}\text { Often associated with viruses or } \\
\text { plasmids }\end{array}$ \\
\hline $\operatorname{arCOG09593}$ & 8 & $\begin{array}{l}\text { Secreted protein with immunoglobulin- } \\
\text { like domain }\end{array}$ \\
\hline $\operatorname{arCOG10866}$ & 8 & Methanosaeta specific \\
\hline $\operatorname{arCOG09761~}$ & 8 & $\begin{array}{l}\text { Large secreted protein; pyrobaculum } \\
\text { specific expansion }\end{array}$ \\
\hline $\operatorname{arCOG} 11121$ & 7 & $\begin{array}{l}\text { Uncharacterized conserved membrane } \\
\text { protein }\end{array}$ \\
\hline $\operatorname{arCOG03316}$ & 7 & $\begin{array}{l}\text { Secreted enzyme present in bacteria and } \\
\text { eukaryotes, duplication in } \\
\text { methanosarcina acetivorans DUF3160 }\end{array}$ \\
\hline $\operatorname{arCOG03631}$ & 7 & $\begin{array}{l}\text { Methanosarcina specific, present in } \\
\text { bacteria }\end{array}$ \\
\hline $\operatorname{arCOG07691}$ & 7 & $\begin{array}{l}\text { Secreted protein associated with } \\
\text { membrane protein of a number of } \\
\text { related arCOGs (e.g., arCOG09771), } \\
\text { mostly beta stranded; pyrobaculum } \\
\text { specific expansion }\end{array}$ \\
\hline $\operatorname{arCOG06827}$ & 7 & $\begin{array}{l}\text { Membrane protein expansion in } \\
\text { Methanosarcina, MGWCP motif, } \\
\text { DUF1673 }\end{array}$ \\
\hline $\operatorname{arCOG10868}$ & 7 & $\begin{array}{l}\text { PD-(D/E)XK nuclease family } \\
\text { transposase }\end{array}$ \\
\hline $\operatorname{arCOG} 10363$ & 7 & $\begin{array}{l}\text { Associated with } \mathrm{Zn} \text {-finger containing } \\
\text { protein from arCOG08887 }\end{array}$ \\
\hline
\end{tabular}

Genes that belong to the mobilome genes are highlighted by bold type
(Mochizuki et al. 2011). In the A. pernix genome, these two proviruses appear as large genomic loci flanked by direct repeats (attachment sites) and parts of the split integrase gene. Each of the proviruses contained approximately 40 ORFs most of which were uncharacterized. Taking these findings into account, we modified our procedure and identified larger islands that consisted of at least 20 genes, with 5 genes from the negative set allowed. These larger islands are expected to better reflect virus-related loci, whereas the smaller islands could contain other integrated elements such as plasmids and transposons. Comparison of the two island sets showed that nearly all larger islands at least partly overlap the smaller island set (the reverse, obviously, is not the case). We mapped identified (pro)viral and plasmid genes (including genes from plasmids that are genomic partitions; see Supplementary Table 2 for details) on both sets of islands. The results suggest that approximately $20 \%$ of the island content can be attributed to the genes encoded in known viruses and plasmids. All the common groups of viruses mentioned above and many previously described plasmids are present in the islands. The distribution of different classes of integrated elements varies considerably even among closely related archaea (Fig. 5). In many cases, it is not possible to determine whether an integrated element represents a plasmid or a virus because many of these elements encompass both viral and plasmid genes.

Compared to thermophiles, dark matter islands in mesophile genomes contain a significantly larger fraction of identifiable integrative elements $\left(27\right.$ vs. $12 \%, \chi^{2}$ $p$ value $\ll 10^{-10}$ ), largely due to the high abundance of plasmids (15 vs. $4 \%, \chi^{2}$ p value $\ll 10^{-10}$ ) (Fig. 2 c). Known viruses comprise a higher fraction of the dark matter islands in thermophiles $\left(9\right.$ vs. $6 \%, \chi^{2} p$ value $3 \times 10^{-9}$ ) (Fig. 2c).

It could be expected that, along with already known ones, the dark matter islands would contain unknown or unusual integrated elements. One of such islands identified in the Archaeoglobus veneficus SNP6 genome and containing an unusual combination of viral-like genes was selected for more detailed characterization as an example of a virus-derived region. Although some bacterial viruses are known to integrate into the genomes of their hosts using cellular recombination machineries (Huber and Waldor 2002; Krupovic and Forterre 2011), the majority of prokaryotic viruses and plasmids encode dedicated enzymes, known as integrases, which mediate their insertion into specific loci of the cellular genomes (She et al. 2004). The most common integration targets for archaeal mobile elements are tRNA genes (She et al. 2004). Analysis of the 
Aeropyrum pernix Sulfolobus islandicus 5714

Sulfolobus islandicus 1551

Thermofilum pendens

Pyrobaculum oguniense Archaeoglobus profundus Archaeoglobus veneficus

Pyrococcus horikoshii

Thermococcus barophilus

Thermococcus gammatolerans

Thermococcus kodakarensis

Methanocaldococcus fervens Methanocaldococcus jannaschii Methanocaldococcus vulcanius

Methanobacterium AL

Methanobacterium SWAN

Methanobrevibacter ruminantium

Methanobrevibacter smithii

Methanococcus aeolicus Methanococcus maripaludis C5 Methanococcus maripaludis $\mathrm{C} 6$ Methanococcus maripaludis $\mathrm{C7}$ Methanococcus maripaludis S2

Methanococcus vannielii SB

Methanococcus voltae $\mathrm{A} 3$

Methanoplanus petrolearius

Methanosaeta concilii

Methanosaeta harundinacea

Methanohalobium evestigatum Methanomethylovorans hollandica

Methanosarcina acetivorans

Halalkalicoccus jeotgali

Haloarcula marismortui

Halobacterium salinarum Halobacterium

Haloferax mediterranei Haloferax volcanii Halogeometricum borinquense Halomicrobium mukohataei Halopiger xanaduensis Haloquadratum walsbyi Haloquadratum walsbyi Halorubrum lacusprofundi Haloterrigena turkmenica Natrialba magadii

Natrinema pellirubrum

Natronobacterium gregoryi

Natronococcus occultus Natronomonas pharaonis halophilic archaeon Nitrososphaera gargensis $0 \%$

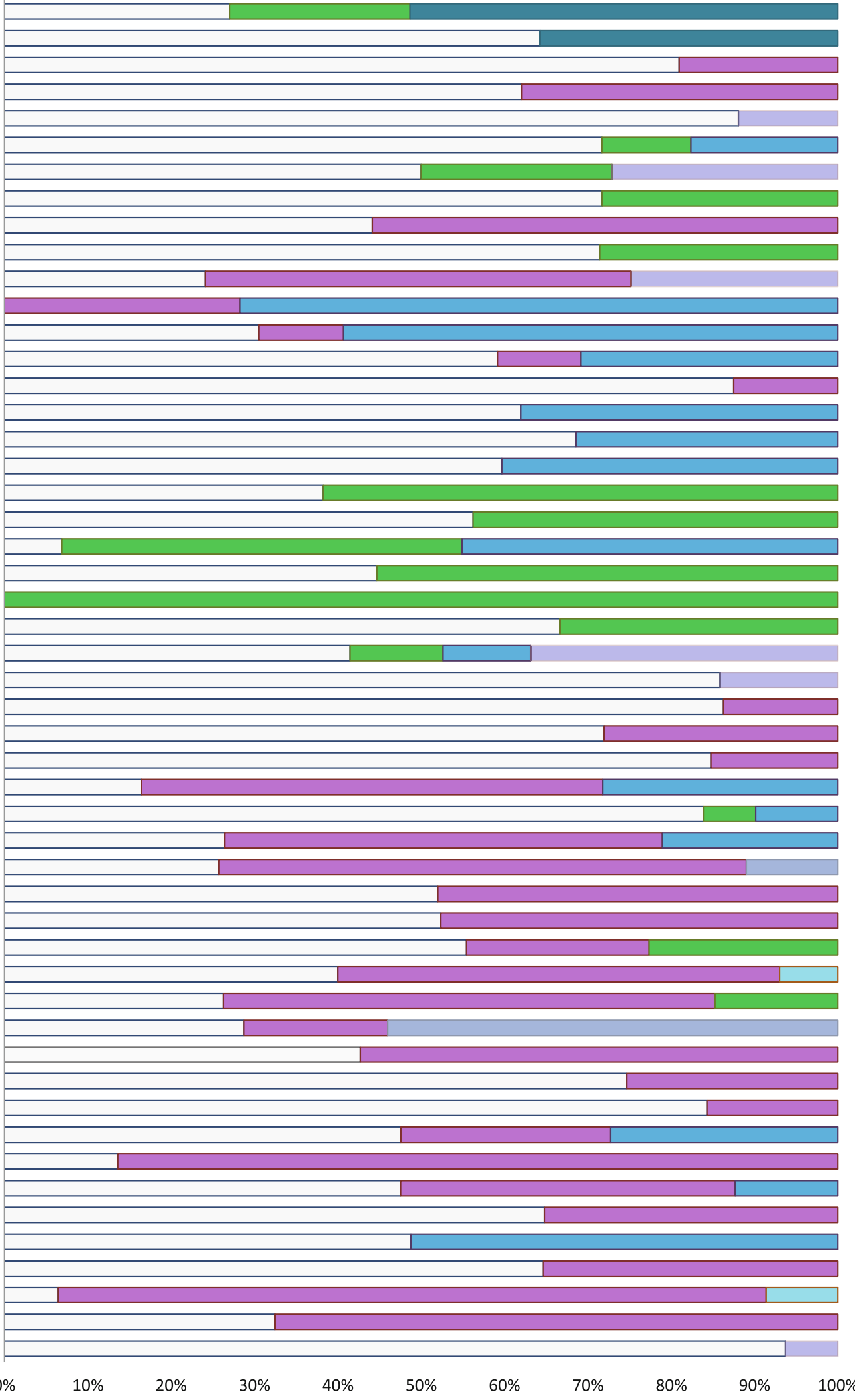

$\square$ Other dark matter genes $\square$ Plasmid $\square$ Integrated element $\square$ Caudovirales $\square$ Fuselloviridae $\square$ Pleolipoviridae $\square$ Sphaerolipoviridae $\square$ Turriviridae

Fig. 5 Distribution of the genes associated with different integrated elements in dark matter islands. The number of genes in each category of integrated elements and the rest of the dark matter genes in the respective genome are shown. Thermophiles are highlighted in red 
A

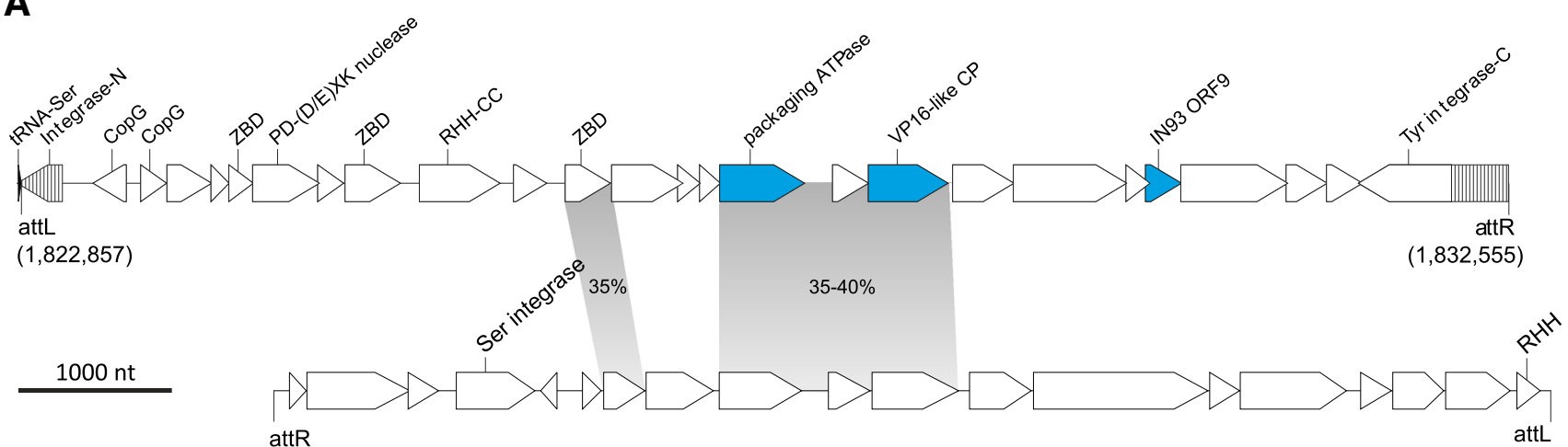

$(579,377)$

$(571,186)$

\section{B}

327401935 | ArcVen-P3 297566179 | MeioSilP1 291294490 | MeioRubP1 495906371 | TP1 27819354 | IN93 257136449 | P23-77

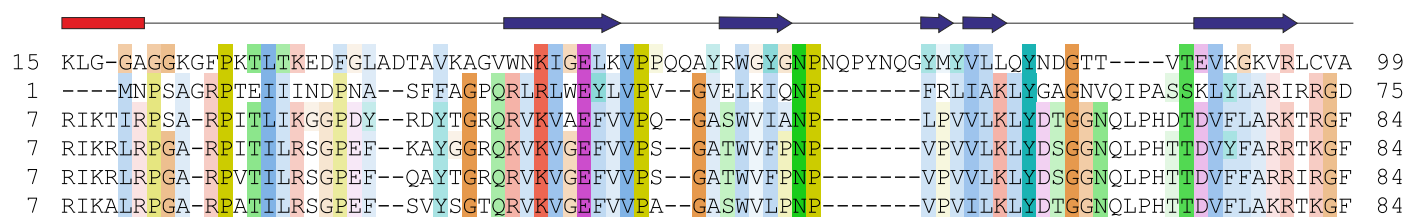

327401935|ArcVen-P3 100 DANELKKDVVFEEREEVLHAAAADITK-QR----------PLPEQGPIAREDDKLIIEFMPDQDGQITAADCD----IRLPVTVYPAR-297566179 | MeioSilP1 76 FEIEDLAEIPYAPYFSLTIDQQLDANEAERI----THVIENTGRMGYAFDEGDRLAILIEST----LAVDTTNPNNRIQFTGLVNN---- 153 291294490 | MeioRubP1 85 DAPEFLGKIQYAGYYDLSEAQQRDAKYYQNILATLSPAKGGVTPQGFAFREGDILEVYVESSA----TPALADARTRIELPVGVDNSTI- 169 495906371|TP1 85 DFPEFLVKAQYASYYDLSEAQQRDAKFYQNILQTASPLYAPTPPQGIVLREGDTLEIYVETDPG--ITVNLNDSRTRIELPVGVDNSNV- 171 27819354 |IN93 85 DFPEFLVKAQYASYYDLSEAQQRDAKYYQNILQTASPLYAPTPPQGIVLREGDTLEIYVETDPG--ITVNLNDSRTRIELPVGVDNSNV- 171 257136449| P23-77 85 DFPEFLAKVQYASYYDLTEAQLRDAKFYQNILQTLSPLRAPQPPQGVVLREGDVLEVYVEAPAG--VTVNLNDPRTRIELPIGVDNSNPT 172

Fig. 6 The putative provirus ArcVen-P3 from Archaeoglobus veneficus SNP6. a Genome maps of putative proviruses residing in the genomes of A. veneficus SNP6 (top; NC_015320) and Dehalococcoides sp. CBDB1 (bottom; NC_007356). The exact nucleotide coordinates for the two proviruses are indicated in the figure. Open reading frames are represented with arrows, indicating the direction of transcription. ArcVen-P3 genes with homologs in bacterial sphaerolipoviruses are shown in blue. The regions of the split ArcVen-P3 integrase gene, which have not been originally annotated, are indicated with stripes. The genes shared between the two

selected region from the A. veneficus SNP6 genome showed that the potential integrated element is adjacent to a tRNA-Ser gene. Following the analysis of potential recombination sites, we identified a pair of perfect direct repeats of 55 nucleotides flanking a genomic region of $9.5 \mathrm{~kb}$. One of the repeats overlapped the tRNA gene, whereas the other one was adjacent to the integrase gene. Such an arrangement is the most common among archaeal integrated viruses and plasmids (Krupovic et al. 2010; She et al. 2004), and is consistent with the site-specific integration of the element, which we denote ArcVen-P3, into the tRNA-Ser gene (Fig. 6a).

Analysis of the ArcVen-P3 gene content (Supplementary Table 3) showed that this element is not closely related to known viruses and plasmids of archaea. Nevertheless, several virus-like genes could be recognized. BlastP searches against the viral protein database showed that proviruses are connected with grey shading and the pairwise identity between the corresponding proteins is indicated. Abbreviations: $Z B D$ Zn-binding domain; $R H H$ ribbon-helix-helix motif; $C C$ coiled-coil domain; $C P$ capsid protein. b Multiple sequence alignment of the predicted capsid proteins (VP16) from ArcVen-P3, bacterial sphaerolipoviruses (P23-77 and IN93) and related proviruses (MeioSilP1, MeioRubP1, TP1) (Pawlowski et al. 2014). Sequences are denoted with their GenBank identifiers. The arrows and rectangles above the alignment denote the experimentally determined secondary structure elements of P23-77 VP16 (PDB ID: 3ZMO) (Rissanen et al. 2013)

ArcVen-P3 encodes two small CopG-like ribbon-helixhelix proteins similar to the transcriptional regulator F55 of Sulfolobus spindle-shaped virus 1 (SSV1) (Fusco et al. 2013). In addition, ArcVen-P3 contains genes for two other proteins with homologues in spindle-shaped viruses, namely an SSV-like integrase and an SSV1 VP2-like protein. The distinguishing feature of SSV-like integrases is that upon recombination the integrase gene is split into two fragments, the $\mathrm{N}$-and $\mathrm{C}$-terminal, that bound the integrated element. Detailed analysis of the termini of ArcVenP3 indeed revealed the region encoding the originally unannotated N-terminal moiety of the SSV-like integrase and furthermore led to extension of the C-terminal integrase fragment (Fig. 6a). The closest homolog of the ArcVen-P3 integrase is encoded in the Thermococcus prieurii virus 1 (Supplementary Table 3) (Gorlas et al. 2012), a spindle-shaped virus recently classified as a member of the 
proposed Deltafusellovirus genus within the family $F u$ selloviridae (Krupovic et al. 2014). VP2 is a virion-associated DNA-binding protein of SSV1 which, unexpectedly, appears to be dispensable for virus viability (Iverson and Stedman 2012; Reiter et al. 1987). A VP2 homolog has been previously detected in the genome of Thermus bacteriophage IN93 (ORF9), a member of the proposed genus Gammasphaerolipovirus within the family Sphaerolipoviridae (Pawlowski et al. 2014). Members of the latter virus family possess icosahedral capsids with an internal membrane and infect either bacterial or archaeal hosts (Pawlowski et al. 2014); these viruses are unrelated to spindle-shaped fuselloviruses. The closest homolog of the VP2-like protein of ArcVen-P3 was found not among archaeal fuselloviruses but rather in the bacteriophage IN9.

Another virus-derived gene of ArcVen-P3 encodes a divergent FtsK-like ATPase related to genome packaging enzymes of viruses with icosahedral capsids and internal membranes (Iyer et al. 2004; Stromsten et al. 2005). The FtsK-like packaging ATPases have so far been exclusively found in viruses with jelly-roll capsid proteins (CP) (Koonin et al. 2006; Krupovic and Bamford 2008b), including members of the Sphaerolipoviridae, suggesting that ArcVen-P3 might also encode a jelly-roll CP. Although BlastP analysis did not allow detection of $\mathrm{CP}$ candidates, HHpred search seeded with the Arcve_2069 sequence resulted in a partial hit to the capsid protein VP16 of the sphaerolipovirus P23-77 infecting Thermus thermophilus (Rissanen et al. 2013). To validate this weak HHpred hit, we generated a multiple sequence alignment of the ArcVen-P3 protein and VP16-like proteins from previously described (Pawlowski et al. 2014) Thermus sphaerolipoviruses and related proviruses (Fig. 6b). Not only the sequence similarity was distributed evenly along the protein length, but the secondary structure elements that constitute the jelly-roll fold of the VP16 protein (Rissanen et al. 2013) were conserved in the VenArc-P3 protein. Furthermore, the genomic location of the VP16-like gene in ArcVen-P3 is consistent with its predicted CP function because VP16-like genes in both P23-77-like viruses and ArcVen-P3 are encoded downstream of the genome packaging ATPase, separated by one gene. The virions of sphaerolipoviruses consist of two jelly-roll CPs, VP16 and VP17, that have been suggested to originate by gene duplication (Rissanen et al. 2013). However, we were unable to detect a homolog of the VP17-like CP in the ArcVen-P3 genome. Collectively, these observations suggest that ArcVen-P3 shares at least two of the viral hallmark proteins, FtsK-like ATPase and VP17-like CP, with sphaerolipoviruses (and additionally an ORF9-like gene with sphaerolipovirus IN93).The genomes of bacterial sphaerolipoviruses P23-77 and IN93 (17 and $19.6 \mathrm{~kb}$, respectively) are considerably larger than the genome of
ArcVen-P3. Therefore, it appears likely that ArcVen-P3 represents an ancestral, simpler state of P23-77/IN93-like sphaerolipoviruses with only one $\mathrm{CP}$ gene. Experimental validation of this hypothesis should provide insights into the origin and evolution of these viruses.

Finally, we noticed that some of the ArcVen-P3 encoded proteins, including those for the putative packaging ATPase and VP16-like CP, produced reciprocal best Blast hits to proteins from Dehalococcoides sp. CBDB1 (Supplementary Table 3). The latter bacterium belongs to the phylum Chloroflexi and is known for its ability to catabolize many of the most toxic chlorinated aromatics and aliphatics by reductive dechlorination (Kube et al. 2005). Analysis of the Dehalococcoides sp. CBDB1 genomic region encompassing the homologs of the ArcVen-P3 genes showed that these genes are also located within an integrated element flanked by perfect direct repeats of 15 nucleotides (Fig. 6a). Notably, instead of the SSV-like tyrosine recombinase, the putative provirus of $D e$ halococcoides encodes an unrelated serine integrase. The similarity between the two putative proviruses, respectively, residing in the archaeal and bacterial genomes highlights them as a potential new group of viruses related to the family Sphaerolipoviridae and traversing the boundary between the cellular domains archaea and bacteria. Detailed analysis of the putative (pro)viruses identified in the course of this project will be published elsewhere (MK, KSM, EVK, PF, DP, in preparation).

Inspection of the smaller islands revealed yet uncharacterized putative elements that encode a protein (arCOG07809, e.g., Mpal_2033 from Methanosphaerula palustris) distantly related to the primase-polymerase (prim-pol) domains of replication proteins from plasmids of Sulfolobus (Lipps 2011; Prato et al. 2008) and Thermococcus (Gill et al. 2014; Krupovic et al. 2013) as well as certain bacterial viruses (Halgasova et al. 2012). All these proteins are members of the large superfamily of archaeaoeukaryotic primases (AEP) which also includes the catalytic subunit of the archaeal and eukaryotic primases, the enzymes responsible for the initiation of DNA replication (Iyer et al. 2005). In different AEP members, the prim-pol domains possess a broad range of enzymatic activities (Gill et al. 2014) and are often fused to a variety of functionally and structurally distinct domains (Iyer et al. 2005). For example, in ORF904 from $S$. islandicus plasmid pRN1, the N-terminal prim-pol domain is followed by superfamily 3 helicase and winged helix-turn-helix (wHTH) domain (Lipps 2011; Lipps et al. 2004). A similar prim-pol protein is encoded by pSSVx which is a fusellovirus satellite virus from $S$. islandicus that combines features of a plasmid and a virus (Arnold et al. 1999; Contursi et al. 2014). However, these proteins are only distantly related to Mpal_2033 and belong to a different arCOG (arCOG06914). Mpal_2033 
Methanoregula formicicum SMSP

$1000 \mathrm{nt}$

NC_019943 2376694..2435603

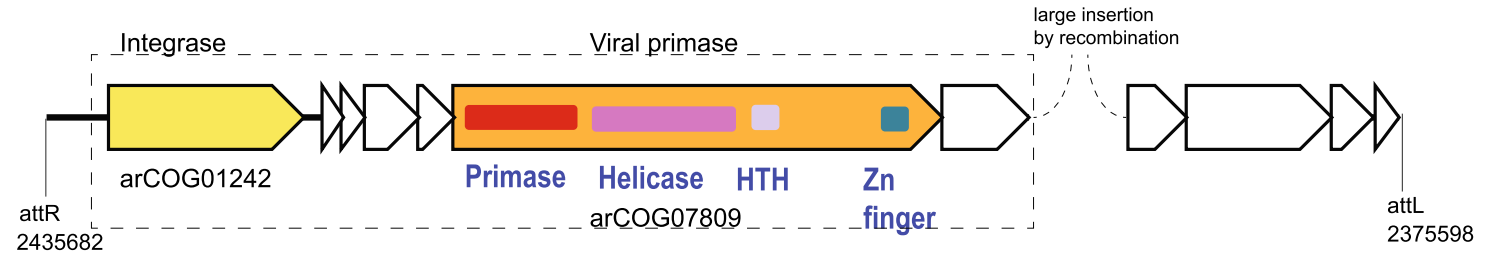

Methanosphaerula palustris E1 9c

NC_011832 1422686..1430307

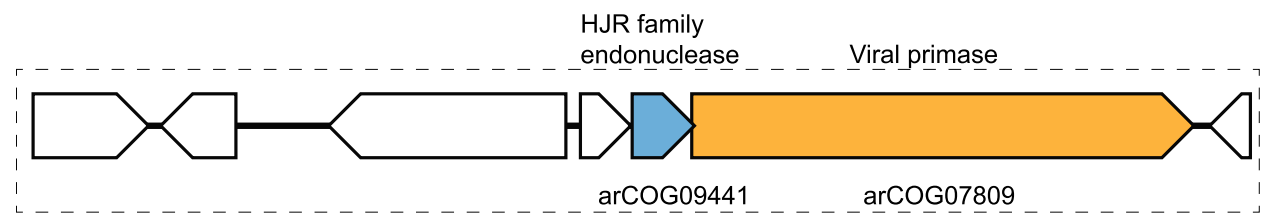

Methanolobus psychrophilus R15

NC_018876 1097687..1103305

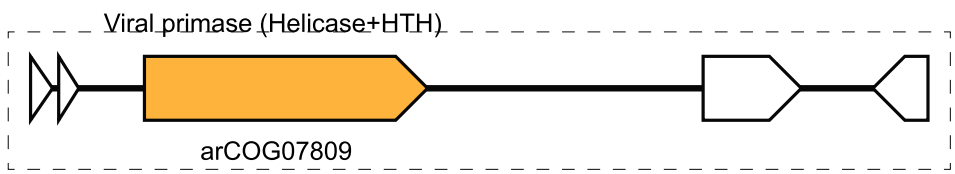

Sulfolobus islandicus L S 215

NC_012589 1357952..1363615

SSV1-lile

ORF_D-335

Viral primase (Helicase+HTH) GIY-YIG nuclease

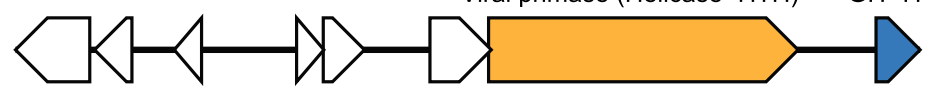

$\operatorname{arCOG07809}$

$\operatorname{arCOG} 07277$

Methanothermobacter marburgensis Marburg NC_014409 101..4365

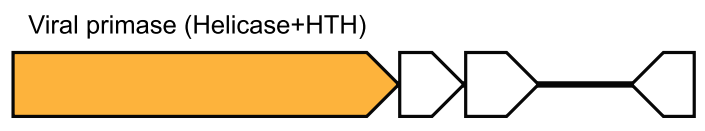

$\operatorname{arCOG07809}$

Candidatus Nitrososphaera_gargensis Ga9 2 NC_018719 2276990..2282428

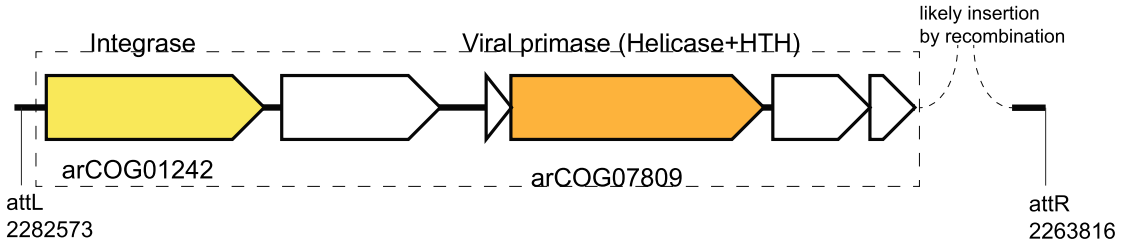

Fig. 7 Neighborhood analysis of putative small integrated elements associated with the novel prim-pol protein of arCOG07809. Designations are the same as in Fig. 4. Domains identified in prim-pol-like protein are shown by colored shapes within the respective gene arrow 
encompasses four domains: primase, Superfamily I helicase, HTH and Zn finger. We identified several Mpal_2033 homologs that lack the primase domain. Figure 7 shows examples of such elements from different archaeal genomes (including both those identified in the small dark matter islands and those detected on the basis of the presence of an arCOG07809-related gene). In addition, standalone proteins closely related to the helicase domain of Mpal_2033 are encoded in the genomes of several fuselloviruses (e.g., C674 protein from Acidianus spindle-shaped virus 1) (Redder et al. 2009), suggesting a role in the initiation of viral DNA replication. Several islands that encompass Mpal_2033 homologs also carry genes for integrases, and for some of them, we identified the integration sites, indicating that these are bona fide integrative elements (Fig. 7). The only two other ORFs from these elements with identifiable sequence similarity to characterized proteins are two endonucleases from different families one of which is related to ORF_D-335 of SSV1, the typical representative of fuselloviruses (Fig. 7). Thus, the small size of the element, the presence of an AEP superfamily (albeit through C-terminal domain only) protein and other ORFs shared with fuselloviruses, and the absence of apparent viral proteins involved in capsid formation is compatible with the readily testable hypothesis that this element is a novel integrated satellite virus.

In addition to the identification of these putative novel viruses, we identified two interesting cases of potential IS elements contained in the smaller islands. One is a distant homolog of an experimentally uncharacterized insertion element of the YhgA family (pfam04754) which contains a PD-(DE)xK superfamily domain. Propagation of these elements is especially prominent in Methanomicrobia (e.g., Mhun_2695 from Methanospirillum hungatei, 11 copies). The second one is a Mutator-like element (MULE) specific for Methanosarcina acetivorans (e.g., MA1896, present in 8 copies in the islands and 13 altogether in the genome, not counting fragments) that was previously identified in eukaryotes only (Babu et al. 2006) but, according to the respective pfam set (PF10551), are also present in a few other archaea and bacteria.

New predicted defense systems identified in dark matter islands

It has been shown that defense genes often form genomic islands and that analysis of such islands allows one to predict new defense systems although the majority of the genes in these islands remain unique or species-specific (Makarova et al. 2013b; Makarova et al. 2011c). Using the procedure described previously (Makarova et al. 2011c), we delineated defense islands in the archaeal genomes analyzed here and then performed cross-mapping of the defense and small dark matter islands. Altogether the overlap constitutes about $15 \%$ of the dark matter. Many of the defense island genes overlap with regions identified as viruses or plasmids (727 of the 3007 detected virus-plasmid-related genes) which is not surprising because many plasmids share defense genes, especially toxin-antitoxin systems, with their hosts (Makarova et al. 2009). Additional 1293 defense genes (approximately $12 \%$ of all genes in the small islands) do not overlap with virus or plasmid regions and might encode novel defense functions.

In particular, we identified two distinct, putative CRISPR-Cas systems that have not been described previously (Fig. 8). Both these CRISPR-Cas variants are so far unique and present in only one genome each, and only a few proteins encoded in these loci show significant sequence similarity with known Cas protein families present in arCOGs (Supplementary Table 1). Despite these unique features, both loci encompass CRISPR-Cas signatures. The putative CRISPR-Cas locus in Thermococcus onnurineus includes three clearly identifiable components, namely Cas 2 ribonuclease that is implicated in spacer integration along with Cas1, Cas4, a PD-DEXK family nuclease, and Cas6, the ribonuclease involved in the processing of pre-crRNA transcript (Makarova et al. 2011a, c). Two other proteins, TON_0322 and TON_0323, respectively, show limited sequence similarity to the proteins of the Csm4 subfamily, which belongs to the Cas5 family and is associated with type III-A CRISPR-Cas systems, and to the Csf2 subfamily of the Cas7 family that is associated with type IV CRISPR-Cas systems (Koonin and Makarova 2013). In addition, this locus encodes two other proteins that consist of 587 and 120 amino acids, respectively, and are predicted to adopt mostly alpha-helical conformation but do not show significant similarity with other proteins. Nevertheless, the general organizational principles of CRISPR-Cas systems (Makarova et al. 2013a, b) imply that these proteins could be large and small subunits of the CASCADE complex, respectively. Moreover, HHpred analysis detected a diverged HD nuclease domain at the $\mathrm{N}$-terminus of the larger protein (Supplementary Table 4), with the same order of the catalytic motifs as the HD domain present in the Cas3 and Cas10d families (Makarova et al. 2006). The Cas2 protein in this locus is highly similar to the Cas2 proteins from other Thermococci, but in those genomes this protein belongs to Type I-A loci. Thus, it seems that this unique system replaced a Type I-A locus specifically in the Thermococcus onnurineus lineage. The evidence from protein sequence analysis and the genomic locus organization does not allow us to classify this system as any of the known CRISPR-Cas subtypes. Considering the absence of the Cas1 gene that is essential for spacer integration, this system is not predicted to be capable of inserting new spacers into the CRISPR cassettes. 
Thermococcus onnurineus NA1

NC $011529296530 . .302053$

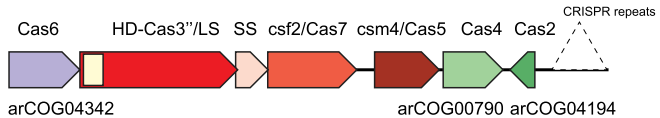

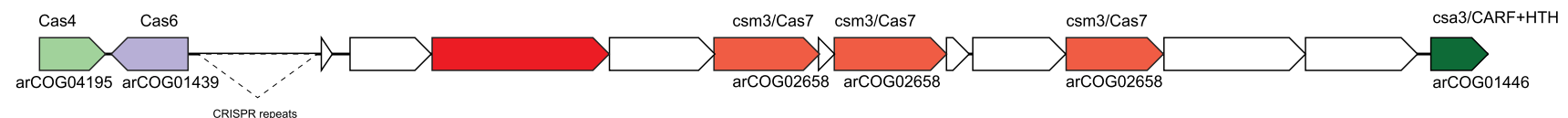

Fig. 8 Neighborhood analysis of two highly derived CRISPR-Cas systems. Designations are the same as in Fig. 4. The Cas gene annotation is based on accepted classification (Koonin and Makarova 2013; Makarova et al. 2011a, b)

Moreover, in $T$. onnurineus, Cas1 is missing altogether although an otherwise intact type III-A CRISPR-Cas system (TON_0892-TON_0898), and additional CRISPR repeat arrays are present elsewhere in the genome. Whether the CRISPR-Cas systems in $T$. onnurineus are in the beginning of the degradation route, function without spacer integration or employ an alternative integration mechanism, is an intriguing problem for experimental study that could shed light on the general principles of CRISPR-Cas functioning.

Another CRISPR-Cas system was identified in Ignisphaera aggregans. The locus also includes clearly identifiable Cas6 and Cas4 family genes and a Csa3-like gene which encodes a predicted transcriptional regulator containing a ligand-binding domain and a HTH domain (Makarova et al. 2011a, b). Three other proteins encoded in this locus, Igag_0617, Igag_0615 and Igag_0612, all show limited similarity to the Csm3 subfamily of the Cas7 family. The HHpred search showed that another protein in this locus, Igag_0619, is a highly diverged version of the Cas10 protein in which all catalytic motifs remain intact (Supplementary Table 4). These observations suggest that the predicted CRISPR-Cas system of Ignisphaera is a highly derived variant of Type III.

New type IV pili-like systems identified in dark matter islands

As pointed out above, predicted secreted proteins comprise $\sim 7 \%$ of the genes encoded in the archaeal dark matter islands. This is likely to be a substantial underestimate because many proteins predicted to contain a single transmembrane domain at the N-terminus are likely to be secreted, given that prediction methods optimized for archaeal signal peptides, to our knowledge, are currently unavailable. Several dark matter islands contain genes encoding various predicted ATPases, in particular those of the VirB11 protein family (9 islands) that are involved in a variety of trafficking functions including the biogenesis of archaeal flagella (archaella) and pili, and substrate transport by type IV secretion systems (Alvarez-Martinez and Christie 2009; Guglielmini et al. 2013; Lassak et al. 2012; Ripoll-Rozada et al. 2013). All of these predicted ATPases are encoded within putative operons that also contain genes coding for multiple predicted membrane and/or secreted proteins which (with a few exceptions) do not share any similarity with the components of experimentally characterized archaeal type IV pili-like systems (Lassak et al. 2012). Thus, these operons likely encode novel secretion and membrane-associated systems (Fig. 9a). The motor ATPases in these loci belong to two distinct subfamilies (Fig. 9a), suggesting that some of these putative secretory systems perform specialized functions and/or that the ATPase genes are extensively exchanged.

An unusual putative secretory system was found in the genome of Methanocaldococcus jannaschii (Fig. 9a). It shares some proteins, such as flagellins/pilins, FlaJ-like pili assembly protein and FlaK-like peptidase A24A with the archaellum, but does not seem to include other typical proteins associated with this archael motility structure, such as FlaG, FlaF, FlaH (Jarrell and Albers 2012). Nor does this locus encode typical pilins found in pili systems characterized in the genome of another methanococcal species, Methanococcus maripaludis ( $\mathrm{Ng}$ et al. 2011). The majority of the proteins in this operon are shared only by a few other species of methanococci. The loci coding for the typical archaellum and the pili system are conserved between $M$. jannaschii and $M$. maripaludis. Thus, the putative novel Type IV pili-like system that we identified in $M$. jannaschii is likely to perform a distinct function specific to a narrow methanococci group.

Other putative membrane-associated detected in the dark matter islands systems found in the dark islands share even fewer genes with known archaeal motility and surface 


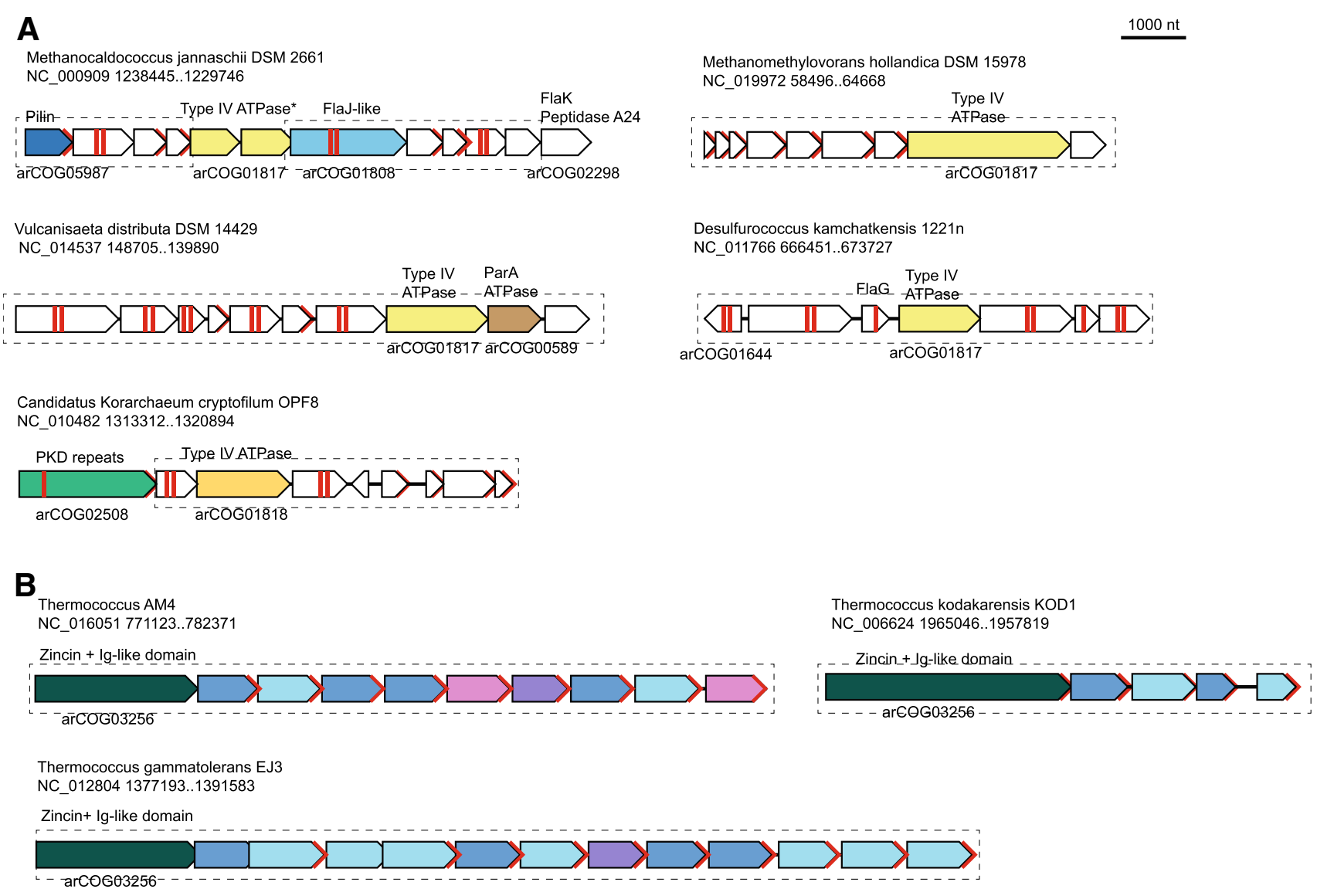

Fig. 9 Neighborhood analysis of the predicted new type IV secretion systems. Designations are the same as in Fig. 4

appendage structures. For example, in a unique system that is encoded on the plasmid pMETHO01 from Methanomethylovorans hollandica, even the VirB11 homolog shows low (albeit significant) sequences similarity to the archaellum FlaI subunits (Fig. 9a).

In addition, we examined in greater detail the most common arCOGs that consist of predicted secreted proteins, e.g., arCOG10027 which is specific for Thermococcus species (Table 2). We found that the loci encoding proteins of this arCOG also contain genes for paralogous predicted secreted proteins of arCOG10028 and arCOG10066 (Fig. 9b). Furthermore, the predicted operons encoding these proteins also contain a gene for a large protein that contains a zincin metallopeptidase and a distinct immunoglobulin-like fold which is often found in surface proteins (Fig. 9b). This peptidase might cleave some peptides from the multiple proteins encoded in the same locus. The loci show remarkable variation between species suggesting that they encode secreted proteins involved in inter-microbial conflicts, such as bacteriocinlike toxins proteins, or quorum sensing.

Collectively, these observations show that archaeal dark matter islands encode a variety of uncharacterized, lineagespecific, membrane-associated and secreted protein complexes. Further comparative genomic and experimental analysis of these systems can be expected to shed new light on archaeal ecology.

\section{Conclusions}

As expected, detailed analysis of the dark matter islands in archaeal genomes shows that these genomic regions are highly heterogeneous and diverse with respect to gene composition and predicted functions. Nevertheless, three distinct but not necessarily independent themes are clearly discernible:

1. Integrated viral genomes and other mobile elements

2. Defense systems

3. Secretory and other membrane-associated systems.

Jointly, mobilome components account for about $22 \%$, defense systems for about $15 \%$, and secreted or membrane proteins for about $31 \%$ of the dark matter islands. The union of all these "known" genes amounts to about $55 \%$ of the gene content of the archaeal dark matter, whereas the rest half of the genes in the islands remain complete unknowns. The most unexpected finding is the striking 
abundance of predicted secreted and membrane proteins encoded in the dark matter islands. Most of these novel membrane-associated and secretory systems function in inter-microbial conflicts and communication, functions that differ even among closely related microbes.

In evolutionary terms, the key trends are fast evolution and horizontal mobility that result in rapid divergence and rearrangement of the "dark" loci. This mode of evolution could be readily predicted for the mobilome and defense systems, but the similar characteristics of the numerous putative novel membrane-associated and secreted systems are unexpected and point to a poorly understood aspect of microbial biology.

Although the overall characteristics of the dark matter are qualitatively similar in thermophiles and mesophiles, predicted membrane proteins are substantially more abundant and secreted proteins are slightly more abundant in thermophiles. The potential functional link of these systems to the lifestyle of thermophiles remains to be explored. Conversely, mesophiles contain many more recognizable proviruses and mobile elements within the dark matter islands. A possible explanation of this difference could be that the current knowledge of the viruses and mobile elements of thermophiles is substantially incomplete, suggesting that novel classes of such elements remain to be discovered.

The principal conclusion of this work is that the abundant dark matter of archaeal genomes is a rich source of novel functional systems and new types of genetic elements many of which are predicted to be involved in defense and various forms of inter-microbial interaction. Further study of the dark matter is likely to shed new light on archaeal ecology. Some of the novelties in the dark matter islands include new variants of CRISPR-Cas systems that have recently stirred major interest owing to their fundamental role in microbial immunity and applications in genome engineering. Conceivably, completely novel defense systems with potential utility as tools of molecular biology can be identified as well.

Acknowledgments KSM, YIW and EVK are supported by intramural funds of the US Department of Health and Human Services (to National Library of Medicine); PF is supported by the European Union's Seventh Framework Programme (FP/2007-2013)/Project EVOMOBIL-ERC Grant Agreement no. 340440; MK was partly supported by the European Molecular Biology Organization (ASTF 82-2014).

Conflict of interests The authors declare that they have no conflict of interests.

Open Access This article is distributed under the terms of the Creative Commons Attribution License which permits any use, distribution, and reproduction in any medium, provided the original author(s) and the source are credited.

\section{References}

Altschul SF, Madden TL, Schaffer AA, Zhang J, Zhang Z, Miller W, Lipman DJ (1997) Gapped BLAST and PSI-BLAST: a new generation of protein database search programs. Nucleic Acids Res 25:3389-3402

Alvarez-Martinez CE, Christie PJ (2009) Biological diversity of prokaryotic type IV secretion systems. Microbiol Mol Biol Rev 73:775-808

Aravind L (2000) Guilt by association: contextual information in genome analysis. Genome Res 10:1074-1077

Arnold HP, She Q, Phan H, Stedman K, Prangishvili D, Holz I, Kristjansson JK, Garrett R, Zillig W (1999) The genetic element pSSVx of the extremely thermophilic crenarchaeon Sulfolobus is a hybrid between a plasmid and a virus. Mol Microbiol 34:217-226

Babu MM, Iyer LM, Balaji S, Aravind L (2006) The natural history of the WRKY-GCM1 zinc fingers and the relationship between transcription factors and transposons. Nucleic Acids Res 34:6505-6520

Barrangou R, Horvath P (2012) CRISPR: new horizons in phage resistance and strain identification. Annu Rev Food Sci Technol 3:143-162

Bellgard MI, Itoh T, Watanabe H, Imanishi T, Gojobori T (1999) Dynamic evolution of genomes and the concept of genome space. Ann N Y Acad Sci 870:293-300

Contursi P, Fusco S, Cannio R, She Q (2014) Molecular biology of fuselloviruses and their satellites. Extremophiles 18:473-489

Cortez D, Forterre P, Gribaldo S (2009) A hidden reservoir of integrative elements is the major source of recently acquired foreign genes and ORFans in archaeal and bacterial genomes. Genome Biol 10:R65

Daubin V, Ochman H (2004) Bacterial genomes as new gene homes: the genealogy of ORFans in E. coli. Genome Res 14:1036-1042

Fusco S, She Q, Bartolucci S, Contursi P (2013) T(lys), a newly identified Sulfolobus spindle-shaped virus 1 transcript expressed in the lysogenic state, encodes a DNA-binding protein interacting at the promoters of the early genes. J Virol 87:5926-5936

Galperin MY, Koonin EV (2000) Who's your neighbor? New computational approaches for functional genomics. Nat Biotechnol 18:609-613

Gill S, Krupovic M, Desnoues N, Beguin P, Sezonov G, Forterre P (2014) A highly divergent archaeo-eukaryotic primase from the Thermococcus nautilus plasmid, pTN2. Nucleic Acids Res 42:3707-3719

Gorlas A, Koonin EV, Bienvenu N, Prieur D, Geslin C (2012) TPV1, the first virus isolated from the hyperthermophilic genus Thermococcus. Environ Microbiol 14:503-516

Guglielmini J, de la Cruz F, Rocha EP (2013) Evolution of conjugation and type IV secretion systems. Mol Biol Evol 30:315-331

Halgasova N, Mesarosova I, Bukovska G (2012) Identification of a bifunctional primase-polymerase domain of corynephage BFK20 replication protein gp43. Virus Res 163:454-460

Huber KE, Waldor MK (2002) Filamentous phage integration requires the host recombinases $\mathrm{XerC}$ and $\mathrm{XerD}$. Nature 417:656-659

Iverson E, Stedman K (2012) A genetic study of SSV1, the prototypical fusellovirus. Front Microbiol 3:200

Iyer LM, Makarova KS, Koonin EV, Aravind L (2004) Comparative genomics of the FtsK-HerA superfamily of pumping ATPases: implications for the origins of chromosome segregation, cell division and viral capsid packaging. Nucleic Acids Res $32: 5260-5279$ 
Iyer LM, Koonin EV, Leipe DD, Aravind L (2005) Origin and evolution of the archaeo-eukaryotic primase superfamily and related palm-domain proteins: structural insights and new members. Nucleic Acids Res 33:3875-3896

Jarrell KF, Albers SV (2012) The archaellum: an old motility structure with a new name. Trends Microbiol 20:307-312

Jones DT (1999) Protein secondary structure prediction based on position-specific scoring matrices. J Mol Biol 292:195-202

Kim H, Kim JS (2014) A guide to genome engineering with programmable nucleases. Nat Rev Genet 15:321-334

Kolsto AB (1997) Dynamic bacterial genome organization. Mol Microbiol 24:241-248

Koonin EV, Galperin MY (1997) Prokaryotic genomes: the emerging paradigm of genome-based microbiology. Curr Opin Genet Dev 7:757-763

Koonin EV, Makarova KS (2013) CRISPR-Cas: evolution of an RNA-based adaptive immunity system in prokaryotes. RNA Biol 10:679-686

Koonin EV, Wolf YI (2008) Genomics of bacteria and archaea: the emerging dynamic view of the prokaryotic world. Nucleic Acids Res 36:6688-6719

Koonin EV, Senkevich TG, Dolja VV (2006) The ancient virus world and evolution of cells. Biol Direct 1:29

Krogh A, Larsson B, von Heijne G, Sonnhammer EL (2001) Predicting transmembrane protein topology with a hidden Markov model: application to complete genomes. J Mol Biol 305:567-580

Krupovic M, Bamford DH (2008a) Archaeal proviruses TKV4 and MVV extend the PRD1-adenovirus lineage to the phylum Euryarchaeota. Virology 375:292-300

Krupovic M, Bamford DH (2008b) Virus evolution: how far does the double beta-barrel viral lineage extend? Nat Rev Microbiol 6:941-948

Krupovic M, Forterre P (2011) Microviridae goes temperate: microvirus-related proviruses reside in the genomes of bacteroidetes. PLoS ONE 6:e19893

Krupovic M, Gribaldo S, Bamford DH, Forterre P (2010) The evolutionary history of archaeal MCM helicases: a case study of vertical evolution combined with hitchhiking of mobile genetic elements. Mol Biol Evol 27:2716-2732

Krupovic M, Spang A, Gribaldo S, Forterre P, Schleper C (2011) A thaumarchaeal provirus testifies for an ancient association of tailed viruses with archaea. Biochem Soc Trans 39:82-88

Krupovic M, Gonnet M, Hania WB, Forterre P, Erauso G (2013) Insights into dynamics of mobile genetic elements in hyperthermophilic environments from five new Thermococcus plasmids. PLoS ONE 8:e49044

Krupovic M, Quemin ER, Bamford DH, Forterre P, Prangishvili D (2014) Unification of the globally distributed spindle-shaped viruses of the archaea. J Virol 88:2354-2358

Kube M, Beck A, Zinder SH, Kuhl H, Reinhardt R, Adrian L (2005) Genome sequence of the chlorinated compound-respiring bacterium Dehalococcoides species strain CBDB1. Nat Biotechnol 23:1269-1273

Lassak K, Ghosh A, Albers SV (2012) Diversity, assembly and regulation of archaeal type IV pili-like and non-type-IV pili-like surface structures. Res Microbiol 163:630-644

Lipps G (2011) Structure and function of the primase domain of the replication protein from the archaeal plasmid pRN1. Biochem Soc Trans 39:104-106

Lipps G, Weinzierl AO, von Scheven G, Buchen C, Cramer P (2004) Structure of a bifunctional DNA primase-polymerase. Nat Struct Mol Biol 11:157-162

Makarova KS, Grishin NV, Shabalina SA, Wolf YI, Koonin EV (2006) A putative RNA-interference-based immune system in prokaryotes: computational analysis of the predicted enzymatic machinery, functional analogies with eukaryotic RNAi, and hypothetical mechanisms of action. Biol Direct 1:7

Makarova KS, Sorokin AV, Novichkov PS, Wolf YI, Koonin EV (2007) Clusters of orthologous genes for 41 archaeal genomes and implications for evolutionary genomics of archaea. Biol Direct 2:33

Makarova KS, Wolf YI, Koonin EV (2009) Comprehensive comparative-genomic analysis of type 2 toxin-antitoxin systems and related mobile stress response systems in prokaryotes. Biol Direct 4:19

Makarova KS, Aravind L, Wolf YI, Koonin EV (2011a) Unification of Cas protein families and a simple scenario for the origin and evolution of CRISPR-Cas systems. Biol Direct 6:38

Makarova KS, Haft DH, Barrangou R, Brouns SJ, Charpentier E, Horvath P, Moineau S, Mojica FJ, Wolf YI, Yakunin AF et al (2011b) Evolution and classification of the CRISPR-Cas systems. Nat Rev Microbiol 9:467-477

Makarova KS, Wolf YI, Snir S, Koonin EV (2011c) Defense islands in bacterial and archaeal genomes and prediction of novel defense systems. J Bacteriol 193:6039-6056

Makarova KS, Wolf YI, Koonin EV (2013a) The basic building blocks and evolution of CRISPR-Cas systems. Biochem Soc Trans 41:1392-1400

Makarova KS, Wolf YI, Koonin EV (2013b) Comparative genomics of defense systems in archaea and bacteria. Nucleic Acids Res 41:4360-4377

Marchler-Bauer A, Anderson JB, Chitsaz F, Derbyshire MK, DeWeese-Scott C, Fong JH, Geer LY, Geer RC, Gonzales NR, Gwadz M et al (2009) CDD: specific functional annotation with the conserved domain database. Nucleic Acids Res 37:D205D210

Marraffini LA, Sontheimer EJ (2010) CRISPR interference: RNAdirected adaptive immunity in bacteria and archaea. Nat Rev Genet 11:181-190

Mochizuki T, Sako Y, Prangishvili D (2011) Provirus induction in hyperthermophilic archaea: characterization of Aeropyrum pernix spindle-shaped virus 1 and Aeropyrum pernix ovoid virus 1 . J Bacteriol 193:5412-5419

Ng SY, Wu J, Nair DB, Logan SM, Robotham A, Tessier L, Kelly JF, Uchida K, Aizawa S, Jarrell KF (2011) Genetic and mass spectrometry analyses of the unusual type IV-like pili of the archaeon Methanococcus maripaludis. J Bacteriol 193:804-814

Okonechnikov K, Golosova O, Fursov M (2012) Unipro UGENE: a unified bioinformatics toolkit. Bioinformatics 28:1166-1167

Olovnikov I, Chan K, Sachidanandam R, Newman DK, Aravin AA (2013) Bacterial argonaute samples the transcriptome to identify foreign DNA. Mol Cell 51:594-605

Parzen E (1962) On estimation of a probability density function and mode. Ann Math Stat 33:1065-1076

Pawlowski A, Rissanen I, Bamford JK, Krupovic M, Jalasvuori M (2014) Gammasphaerolipovirus, a newly proposed bacteriophage genus, unifies viruses of halophilic archaea and thermophilic bacteria within the novel family Sphaerolipoviridae. Arch Virol 159:1541-1554

Pei J, Kim BH, Grishin NV (2008) PROMALS3D: a tool for multiple protein sequence and structure alignments. Nucleic Acids Res 36:2295-2300

Petersen TN, Brunak S, von Heijne G, Nielsen H (2011) SignalP 4.0: discriminating signal peptides from transmembrane regions. Nat Method 8:785-786

Prangishvili D (2013) The wonderful world of archaeal viruses. Annu Rev Microbiol 67:565-585

Prangishvili D, Koonin EV, Krupovic M (2013) Genomics and biology of rudiviruses, a model for the study of virus-host interactions in archaea. Biochem Soc Trans 41:443-450 
Prato S, Vitale RM, Contursi P, Lipps G, Saviano M, Rossi M, Bartolucci S (2008) Molecular modeling and functional characterization of the monomeric primase-polymerase domain from the Sulfolobus solfataricus plasmid pIT3. FEBS J 275:4389-4402

Redder P, Peng X, Brugger K, Shah SA, Roesch F, Greve B, She Q, Schleper C, Forterre P, Garrett RA et al (2009) Four newly isolated fuselloviruses from extreme geothermal environments reveal unusual morphologies and a possible interviral recombination mechanism. Environ Microbiol 11:2849-2862

Reiter WD, Palm P, Yeats S, Zillig W (1987) Gene expression in archaebacteria: physical mapping of constitutive and UV-inducible transcripts from the Sulfolobus virus-like particle SSV1. Mol Gen Genet 209:270-275

Ripoll-Rozada J, Zunzunegui S, de la Cruz F, Arechaga I, Cabezon E (2013) Functional interactions of VirB11 traffic ATPases with VirB4 and VirD4 molecular motors in type IV secretion systems. J Bacteriol 195:4195-4201

Rissanen I, Grimes JM, Pawlowski A, Mantynen S, Harlos K, Bamford JK, Stuart DI (2013) Bacteriophage P23-77 capsid protein structures reveal the archetype of an ancient branch from a major virus lineage. Structure 21:718-726

Sencilo A, Roine E (2014) A glimpse of the genomic diversity of haloarchaeal tailed viruses. Front Microbiol 5:84
She Q, Shen B, Chen L (2004) Archaeal integrases and mechanisms of gene capture. Biochem Soc Trans 32:222-226

Siew N, Fischer D (2003) Unravelling the ORFan Puzzle. Comp Funct Genomics 4:432-441

Soding J, Biegert A, Lupas AN (2005) The HHpred interactive server for protein homology detection and structure prediction. Nucleic Acids Res 33:W244-W248

Stromsten NJ, Bamford DH, Bamford JK (2005) In vitro DNA packaging of PRD1: a common mechanism for internal-membrane viruses. J Mol Biol 348:617-629

Swarts DC, Jore MM, Westra ER, Zhu Y, Janssen JH, Snijders AP, Wang Y, Patel DJ, Berenguer J, Brouns SJ et al (2014) DNAguided DNA interference by a prokaryotic argonaute. Nature 507:258-261

Wolf YI, Makarova KS, Yutin N, Koonin EV (2012) Updated clusters of orthologous genes for archaea: a complex ancestor of the archaea and the byways of horizontal gene transfer. Biol Direct 7:46

Yin Y, Fischer D (2006) On the origin of microbial ORFans: quantifying the strength of the evidence for viral lateral transfer. BMC Evol Biol 6:63 